\title{
Seismicity and crustal structure in the vicinity of the southern Itoigawa-Shizuoka Tectonic Line
}

\author{
Yannis Panayotopoulos ${ }^{1}$, Naoshi Hirata ${ }^{1}$, Hiroshi Sato ${ }^{1}$, Takaya Iwasaki ${ }^{1}$, Aitaro Kato ${ }^{1}$, \\ Kazutoshi Imanishi ${ }^{2}$, Yasuto Kuwahara ${ }^{2}$, and Ikuo $\mathrm{Cho}^{2}$ \\ ${ }^{1}$ Earthquake Research Institute, the University of Tokyo, Tokyo 113-0032, Japan \\ ${ }^{2}$ Geological Survey of Japan, AIST, Tsukuba, Ibaraki 305-8567, Japan
}

(Received January 13, 2009; Revised August 28, 2009; Accepted November 20, 2009; Online published March 4, 2010)

\begin{abstract}
The southern part of the Itoigawa-Shizuoka Tectonic Line represents the boundary between the rapidly uplifting Akaishi range and the Kofu basin. The tectonic relation between the different parts of the fault system and the surrounding geological units is yet to be fully explained. In order to reveal seismic activity that might be related to the southern segments of the fault system, a seismic array observation was conducted in the autumn of 2005 . The arrival times of 434 local earthquakes, two vibroseis shots and eleven explosive shots were used in a joint inversion to determine earthquake locations and a 3-D velocity structure of the crust. The relocated events are in good correlation with the estimated deeper extension of the active faults in the area. The seismic velocity model jointly obtained coincides with the geological structure in the area of study. In particular, a thick moderately low $V_{p}$ zone was found beneath the Akaishi range and a high velocity zone beneath the Kofu basin. The moderately low velocity was attributed to the relatively young sedimentary rocks that form the accretionary prism units of the SW Japan arc and the high velocity to the older igneous rocks constituting the Izu-Bonin arc crust.
\end{abstract}

Key words: Double-difference tomography, seismic velocity structure, arc-arc collision, seismicity, ItoigawaShizuoka Tectonic Line, Japan.

\section{Introduction}

Many large intraplate earthquakes occur in the Japanese islands. These events take a heavy toll in human lives and severely damage the infrastructure of the affected area. The area along the Itoigawa-Shizuoka Tectonic Line (ISTL) has the highest probability of a major inland event occurring in the whole of Japan (The Headquarters for Earthquake Research Promotion, 2007). The ISTL is a major tectonic structure that divides the Honshu island of Japan into NE and SW parts (e.g.,Yabe, 1918; Kato, 1992). The ISTL is divided into three regions according to the dip direction of the local fault segments (Fig. 1). The northern ISTL between Itoigawa and Matsumoto forms an east dipping low angle thrust fault (e.g., Sato et al., 2004). The central part surrounding Lake Suwa forms a strike slip fault (e.g., Fujimori, 1991). Finally the southern part of the ISTL forms a west dipping thrust fault (e.g., Ikeda et al., 2009). The southern ISTL near the Kofu basin consists of two parallel thrust fault systems identified by most researchers as the geological ISTL (Hakushu, Hoouzan and Onajika-toge faults) on the western side, and the neotectonically active ISTL (Shimotsuburai and Ichinose faults) on the eastern side (e.g., Kumamoto and Ikeda, 1993). Should an earthquake happen in one of these faults, it would devastate Matsumoto and Kofu cities and the toll on human life would be

Copyright (c) The Society of Geomagnetism and Earth, Planetary and Space Sciences (SGEPSS); The Seismological Society of Japan; The Volcanological Society of Japan; The Geodetic Society of Japan; The Japanese Society for Planetary Sciences; TERRAPUB.

doi:10.5047/eps.2009.11.007 high. Due to its significance the Japanese Ministry of Education, Science and Technology, Sports and Culture has initiated a project entitled "A High Priority Investigation in the ISTL Fault Zone" especifically to reevaluate the seismic hazard in the area.

The geological ISTL constitutes the boundary between the Cretaceous-Tertiary accretionary prism of the southwest Japanese arc to the west and the Izu-Bonin volcanic arc complex to the east (Kano et al., 1990; Kano, 2002) (Fig. 2). The collision of the Izu-Bonin arc with the outer zone rocks of the Japanese arc has greatly deformed and rotated counterclockwise the Akaishi mountain range to the west of the ISTL, with a maximum rotation angle of $55^{\circ}$ (Kano et al., 1990). The Izu-Bonin arc crust to the east of the ISTL is divided into four main terranes according to the time they collided with the Japanese arc (Amano, 1991; Takagi et al., 1993; Soh et al., 1998). The Koma block is located on the footwall of the geological ISTL and was the first part of the Izu-Bonin arc crust to collide with the outer zone rocks of the southwest Japanese arc in the middle Miocene (Koyama, 1990, 1991, 1998). The collision continued through the Miocene till the late Pliocene with the Misaka, Tanzawa and Izu terranes being accreted in turn against the Honshu Island arc crust. The neotectonically active ISTL represents the boundary between the Koma block and the Kofu basin.

In the southern ISTL there have been no detailed studies that enable us to come to solid conclusions about the crustal structure in the area and the deeper extension of the faults. Imanishi et al. (2006) have solved the focal mechanism so- 


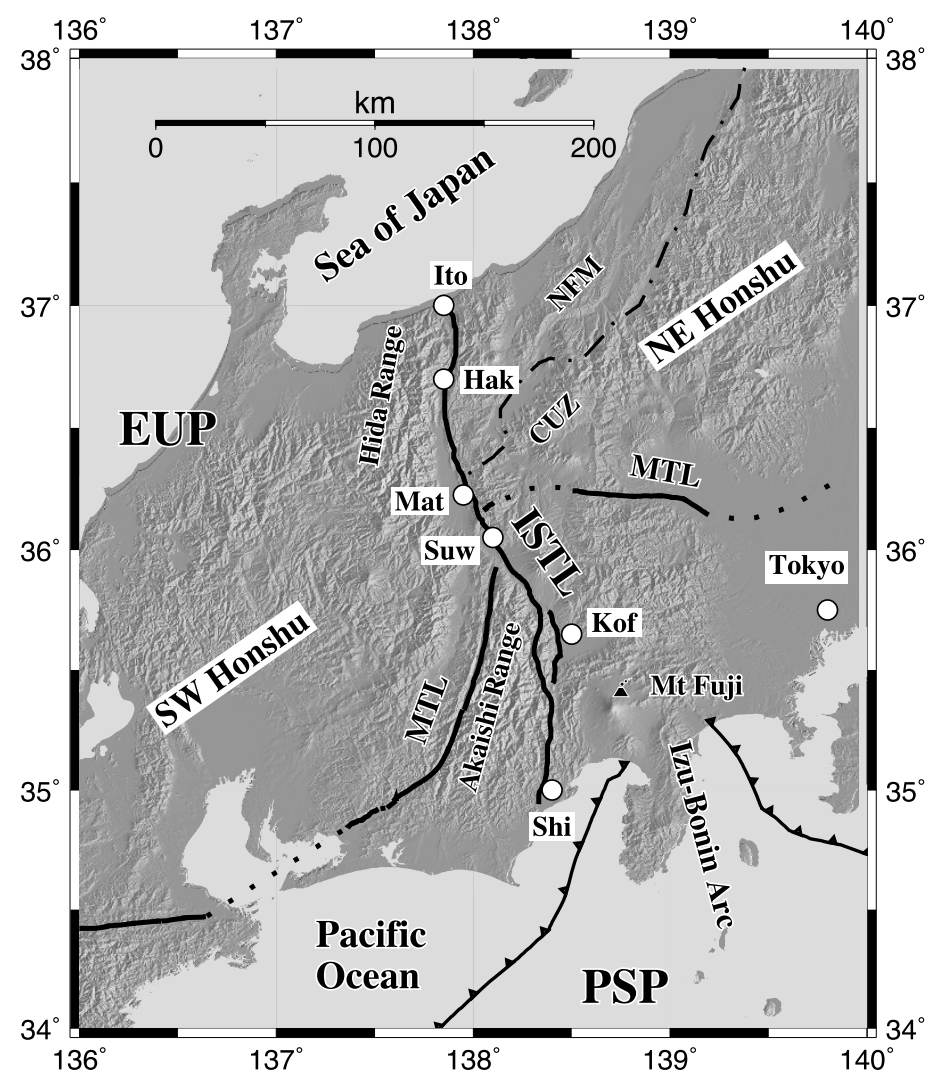

Fig. 1. Map of the Itoigawa-Shizuoka Tectonic Line (ISTL) as a boundary splitting the Honshu Island into NE and SW parts. The black solid lines represent surface traces of the various segments of the ISTL and the Median Tectonic Line (MTL)—Ito: Itoigawa city; Hak: Hakuba village; Mat: Matsumoto city; Suw: Lake Suwa; Kof: Kofu city; Shi: Shizuoka city; Tokyo: Tokyo metropolitan area; NFM: Northern Fossa Magna rift basin; CUZ: Central Uplift Zone; EUP: Eurasia plate; PSP: Philippine Sea plate; Izu-Bonin Arc: Northern tip of the Izu-Bonin Arc volcanic front.

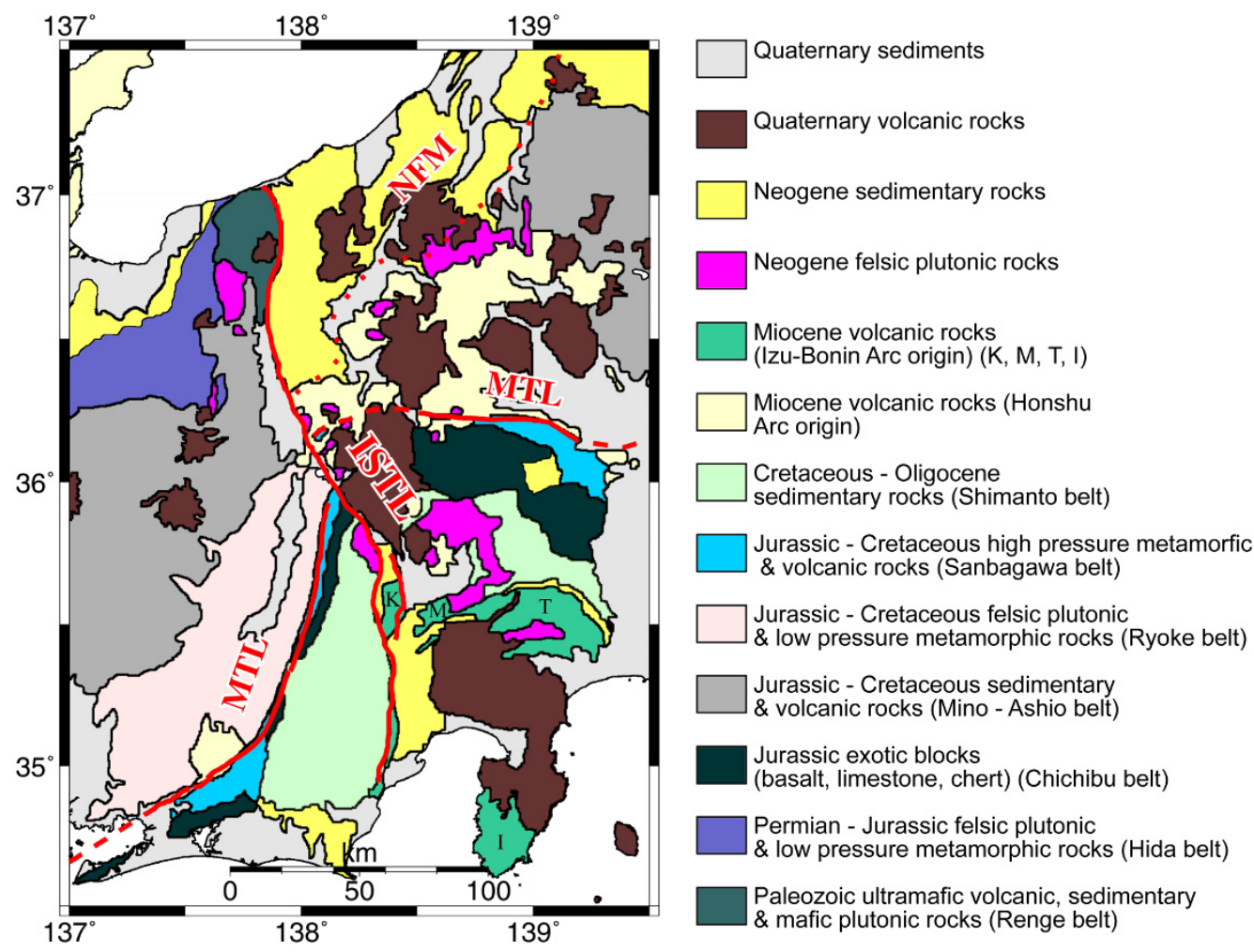

Fig. 2. Geologic setting of the Itoigawa-Shizuoka Tectonic Line (ISTL), Median Tectonic Line (MTL) and the Northern Fossa Magna rift basin (NFM), (Isozaki, 1996; Taira, 2001; Geological Survey of Japan, 2003). K, M, T and I represent the Koma, Misaka, Tanzawa and Izu accreted terranes of the Izu-Bonin Arc crust respectively. 
lutions of 83 events in the area and proved that they are in accordance with the regional deformation estimated by geological studies and by the slip sense of the ISTL faults. Nakamichi et al. (2007) have done a detailed $P$-wave velocity $\left(V_{p}\right), S$-wave velocity $\left(V_{s}\right)$ and $V_{p} / V_{s}$ tomography study beneath Mount Fuji and some parts of their tomogram cover the east side of the ISTL fault system. Recently, Ikeda et al. (2009) conducted a shallow seismic reflection profile and gravity measurements along the ISTL in the Kofu basin. From their observations they have proposed that the southern ISTL forms a low angle thrust fault that extends into the lower crust forming an active nappe structure. On a regional scale (i.e., hundreds of $\mathrm{km}$ in scale), the structure of the crust and the upper mantle in central Japan has been revealed by tomography studies (Nakajima and Hasegawa, 2007; Kamiya and Kobayashi, 2007). The grid spacing in their studies, however, is limited by the spacing of the online seismic network stations in the area and is $0.2^{\circ}$ and $0.1^{\circ}$ in horizontal direction and $15 \mathrm{~km}$ and $8 \mathrm{~km}$ in depth respectively. Furthermore, the resolution of these studies does not provide adequate details on the structure of the crust along the ISTL fault system. There is also great controversy regarding the slip rate and recurrence interval of the various fault segments of the southern ISTL. Previously conducted trench excavations across the Ichinose fault, revealed dip slip rates as low as 0.3 to $0.5 \mathrm{~mm} / \mathrm{yr}$ and a recurrence interval greater than 5,000 yr (Toda et al., 2000). Later trench excavations resulted in a recurrence interval of approximately 3,200 yr and combined with geomorphological observations set the total deformation rate up to 3.5$3.7 \mathrm{~mm} / \mathrm{yr}$ (Miura et al., 2002). More recent seismic reflection profiling and gravity measurements across these faults suggest a slip rate as high as $7.5-11 \mathrm{~mm} / \mathrm{yr}$ (Ikeda et al., 2009).

In order to reveal the crustal structure along the southern parts of the ISTL, it is essential to observe and accurately locate the local seismicity in the area. The present study uses seismic data observed by both the temporary and online station networks in order to image a local detailed velocity model for the southern ISTL region. The near-surface velocity model correlated well with the surface geological structures that have been published (Geological Survey of Japan, 2003) and their deep extensions were delineated. Also investigated is the relationship between the regional seismicity and the deep structure of the ISTL fault system. Finally, we proposed a model for the tectonic evolution of the southern ISTL.

\section{Seismic Array Observation}

The online permanent seismographic network in the vicinity of the ISTL fault system consists of 109 stations (Fig. 3(a)). These stations are spread along ISTL with an average spacing of $20 \mathrm{~km}$, but large areas in the southern ISTL have no station for more than $40 \mathrm{~km}$. In order to reveal seismic activity, which may be related to the ISTL activities, we deployed two dense arrays of offline seismic stations in the south part of ISTL. A dense local array distribution was chosen over a uniform distribution in the entire area in order to capture a detailed image of the crustal changes across the southern ISTL fault segments rather than to obtain a more

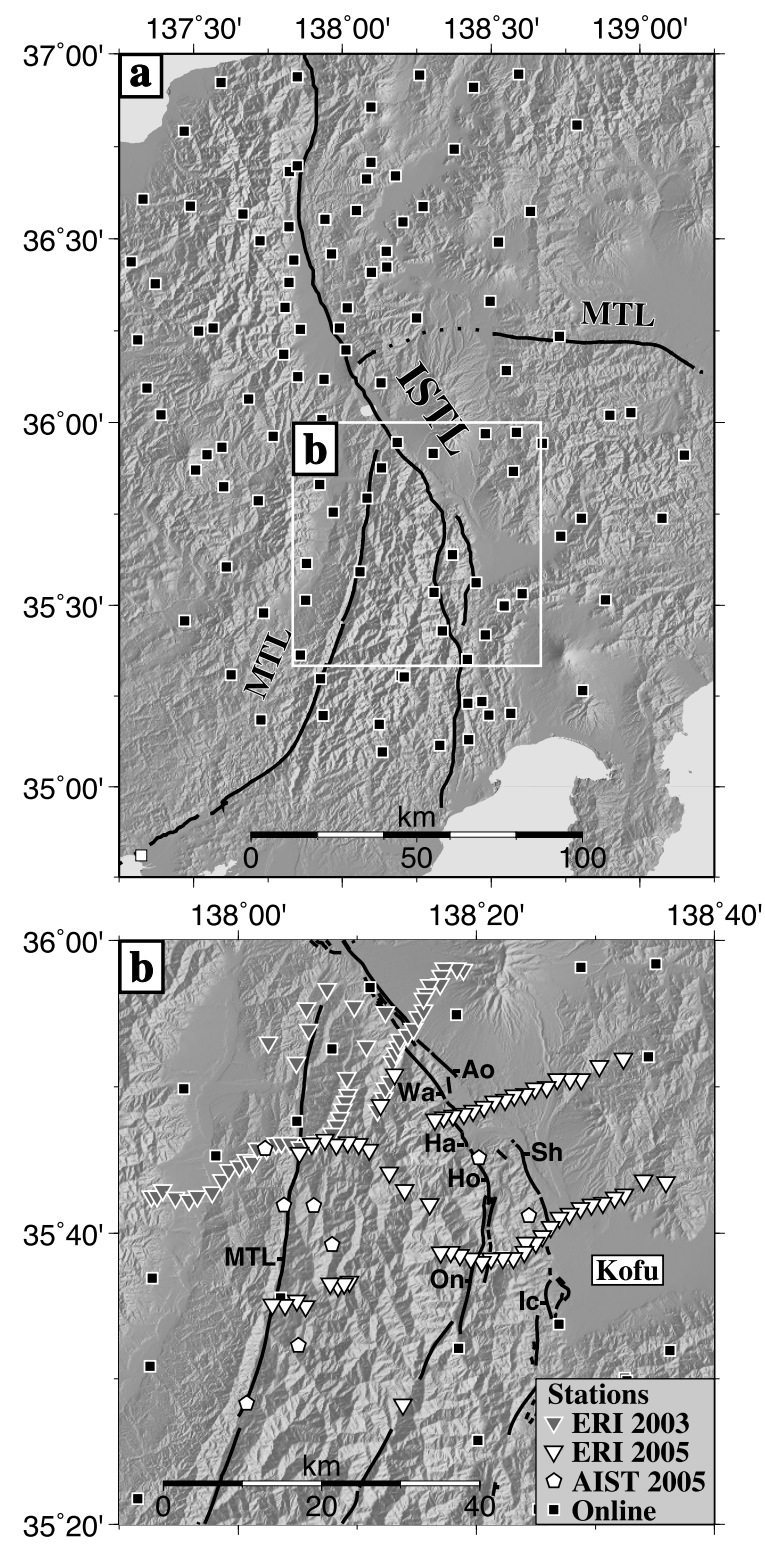

Fig. 3. Distribution of the online permanent seismograph network and the offline temporary seismic stations along the ISTL. (a) Online station distribution (black squares) in the wide area along ISTL. The white frame represents the area of study. (b) Close up on the fault segments of the southern ISTL and their relative location with the offline temporary stations. The Wakamiya (Wa), Aoyagi (Ao), Hakushu (Ha), Houzan (Ho) and Onajika-toge faults constitute the geological ISTL, while the Shimotsuburai fault (Sh) and Ichinose fault group (Ic) constitute the neotectonically active ISTL. Grey inverted triangles: offline stations deployed by the Earthquake Research Institute (ERI) from 25/08/2003 to $16 / 10 / 2003$. White inverted triangles: offline stations deployed by the ERI from $15 / 09 / 2005$ to $23 / 12 / 2005$. White pentagons: offline stations deployed by the Geological Survey of Japan (GSJ, AIST) from $05 / 09 / 2005$ to $30 / 11 / 2005$.

general view of the crust along ISTL.

The first linear array in the present study was deployed across the Wakamiya and Aoyagi faults and run for a 2month period from 25 August 2003 to 16 October 2003 (Fig. 3(b)). The array consisted of 49 stations with a spacing of $1 \sim 1.5 \mathrm{~km}$ and nine additional stations distributed in the surrounding area. We used $1 \mathrm{~Hz}$-seismometers of which waveforms had been continuously recorded by removable HDD recorders that were run on alkaline batteries 
(Shinohara et al., 1997). The recorders utilized a Global Positioning System (GPS) receiver to maintain the accuracy of the internal clock of the recorder. This configuration enabled us to have a one month continuous recording at $200 \mathrm{~Hz}$ sampling rate before the batteries depleted.

In 2005 we moved further south and deployed 60 stations in two parallel linear arrays from 15 Sep. 2005 to 23 Dec. 2005. We covered the Hakushu fault area with a linear array of 25 stations and the Onajika-toge and Shimotsuburai faults with 30 stations at an average spacing of $1.5 \mathrm{~km}$. In addition, five stations were deployed in between the linear arrays. Parallel to the linear array stations, the Geological Survey of Japan (GSJ, AIST) deployed eight offline stations scattered in the southern ISTL area that took continuous recordings from 8 Sep. 2005 to 30 Nov 2005 (Imanishi et al., 2006). In total 235 stations were used for the present study.

\section{Data Analysis}

Our combined dataset consists of 89 events recorded during the 2003 observation and 345 events during the 2005 observation (Fig. 4). Also included are two vibroseis shots from the 2003 observation and eleven explosive shots that were scheduled in the same period as the 2005 observation for a reflection study (Ikeda et al., 2009). Several of these events, which have not been located by the Japanese Meteorological Agency (JMA), were well located using our temporary stations. We manually picked $P$ and $S$ phases from the waveform data recorded by the local permanent network and our temporary station arrays. Thus 20,723 $P$ phase arrivals and 19,797 $S$ phase arrivals were obtained. The total amount of arrival times is about six times that picked by the JMA. In order to accurately determine the hypocenters, a maximum likelihood estimation algorithm (Hirata and Matsu'ura, 1987) was applied. Furthermore, a double difference dataset was created by linking events that were less than $5 \mathrm{~km}$ apart and were commonly observed at least at six stations. This selection provided us with 9,675 $P$ and 9,723 $S$ double difference times with an average distance between linked events of $1.8 \mathrm{~km}$. These events were reprocessed using the Double Difference tomography method (Zhang and Thurber, 2003), in order to obtain a detailed 3D seismic wave velocity structure of the crust in the surveyed area.

The $V_{p}$, and $V_{s}$ was calculated at nodes of a 3D grid, with $20 \times 11 \times 13$ nodes at $X-, Y$ - and $Z$ - directions, respectively (Fig. 4). The $X$-axis of the coordinate system was rotated $17^{\circ}$ counter-clockwise from the east in order to be parallel with our station arrays. The grid nodes on the $X$-axis were set at $5 \mathrm{~km}$ spacing for the central $60 \mathrm{~km}$ and $15 \mathrm{~km}$ or $20 \mathrm{~km}$ in the perimeter. On the $Y$-axis the grid nodes were put on 9 lines at $-56,-32,-16,-8,0,8,16,32,56 \mathrm{~km}$, so that the -8 and $8 \mathrm{~km}$ lines overlap with our two array stations. At depth we have grid nodes at $Z=0,3,6,9$, $12,16,20,30,35,100$ and $200 \mathrm{~km}$ below sea level. As an initial velocity model, we utilized a simple $1 \mathrm{D} P$-wave velocity model with the $V_{p} / V_{s}$ ratio fixed to 1.73 (Fig. 5). This model represents the average $P$ wave velocity struc-

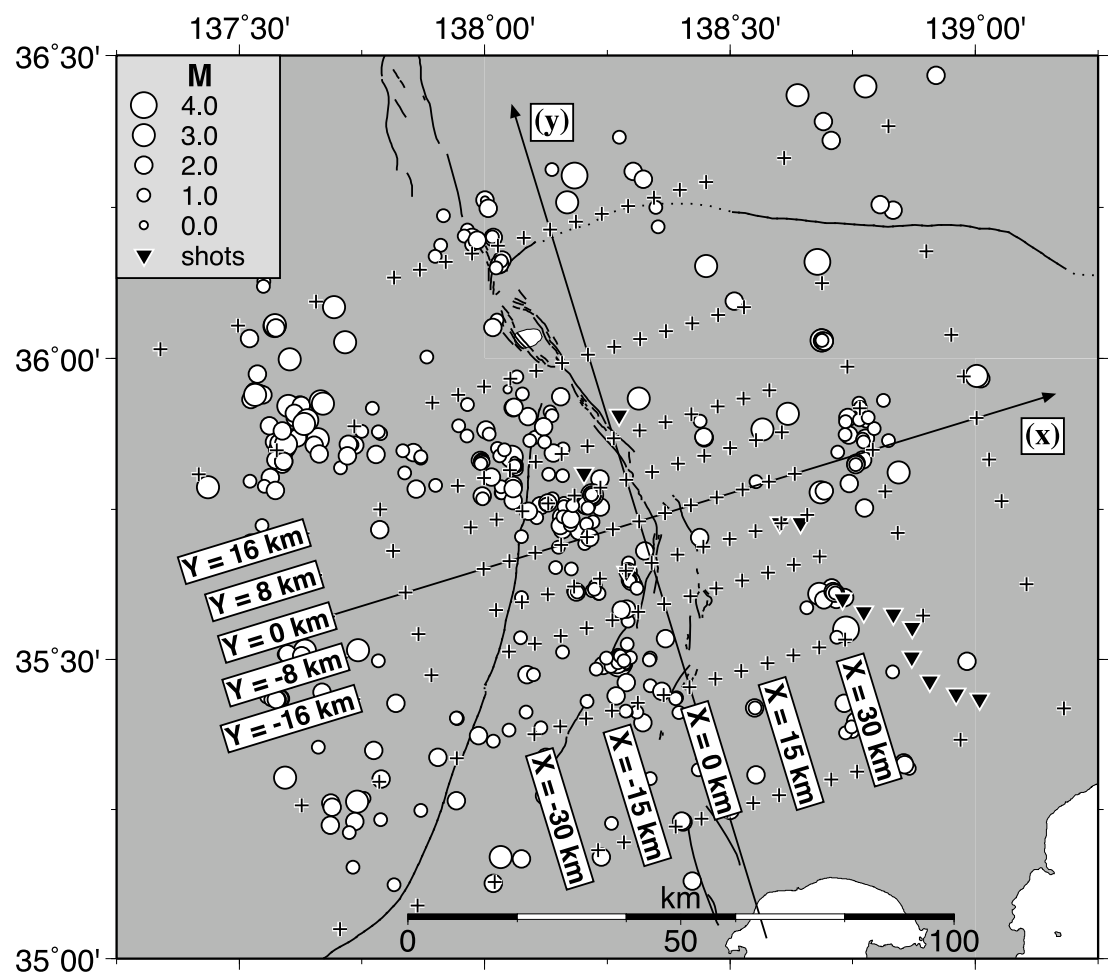

Fig. 4. Event distribution, shot locations and grid node distribution used for the tomographic inversion. The $X$-axis is rotated counterclockwise $17^{\circ}$ to the north and the spacing of the grid nodes in the $y$ direction is set to $8 \mathrm{~km}$ so that the nodes at $y=8 \mathrm{~km}$ and $y=-8 \mathrm{~km}$ overlap with the 2005 offline temporary seismic station arrays. White circles: Earthquakes scaled according to magnitude. Black inverted triangles: Vibroseis and explosive shot location. Black crosses: $X-Y$ distribution of grid nodes. Nodes are set at depths of $0,3,6,12,16,20,30,35,100$ and $200 \mathrm{~km}$ and $Z$-axis is assumed positive downwards. 


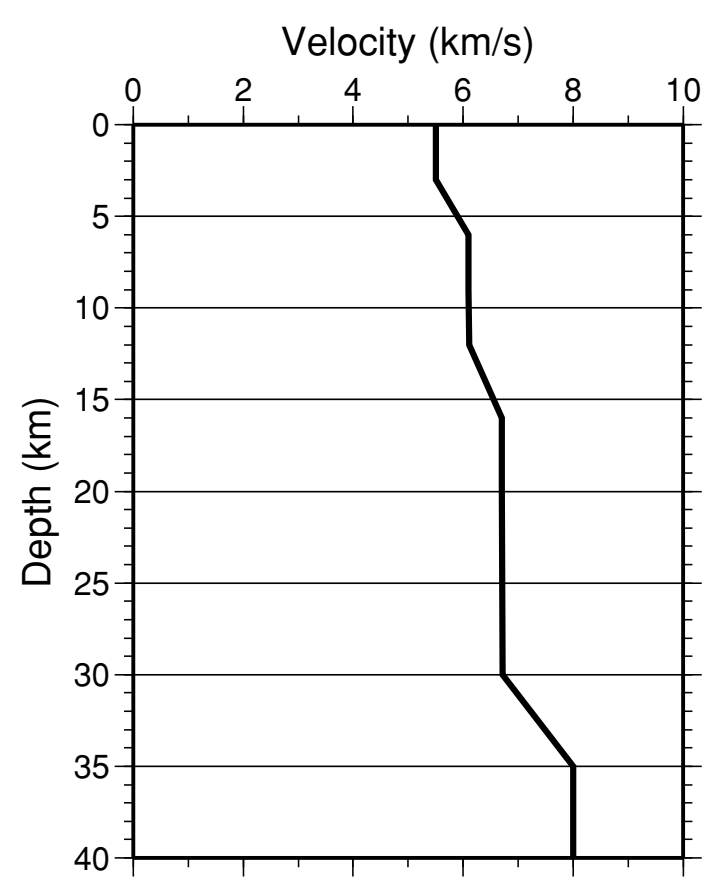

Fig. 5. 1-D $P$-wave velocity model used for the hypocenter determination after picking and as the initial model for the inversion. The $V_{p} / V_{s}$ ratio was set to 1.73 .

ture of the crust and upper mantle underneath the Japanese arc (Zhao et al., 1992). Since picking errors of first arrivals for the $S$ wave are larger than those for the $P$ wave, the $S$ wave arrival time data were down-weighted during the inversion procedure (weight applied 0.8). The double difference (DD) algorithm was applied iteratively eight times while adjusting the slowness weighting parameters accordingly (Zhang and Thurber, 2003). In the first four iterations, the absolute data were weighted ten times higher than the DD data in order to get a detailed structure along the ray paths, and next the DD data were weighted two times higher than the absolute in order to resolve the local structure surrounding the hypocenters. After testing smoothing weightings of $5,10,15,20$ and 30 , we favored the model with a smoothing weighting of 15 for the final results. The final 3D velocity model resulted in a $64 \%$ reduction of the root-mean-square (RMS) travel time residuals from an initial RMS of $297 \mathrm{~ms}$ to a final $106.5 \mathrm{~ms}$ after eight iterations. A good fitting for the absolute $P$ wave travel time arrival was achieved with a mean value for all stations with $\mu=2$ ms and the standard deviation $\sigma=91 \mathrm{~ms}$ (Fig. 6). The $S$ wave fitting is less accurate than the $P$ wave with $\mu=8 \mathrm{~ms}$ and $\sigma=147 \mathrm{~ms}$. This is partly due to the reduced accuracy of the $S$ wave arrival time picking.

The reliability of the tomography inversion results was evaluated by means of a checkerboard resolution test (CRT) (Humphreys and Clayton, 1988). We assigned $\pm 5 \%$ velocity perturbations of the initial velocity model and $50 \mathrm{~ms}$ and $100 \mathrm{~ms}$ random noise for the $P$ and $S$ wave arrival time respectively, and calculated synthetic data using the source-receiver distribution as for the real data. The synthetic dataset was inverted with the initial unperturbated velocity model using the same inversion parameters. The checkerboard patterns were satisfactorily reproduced in a (a) P phase

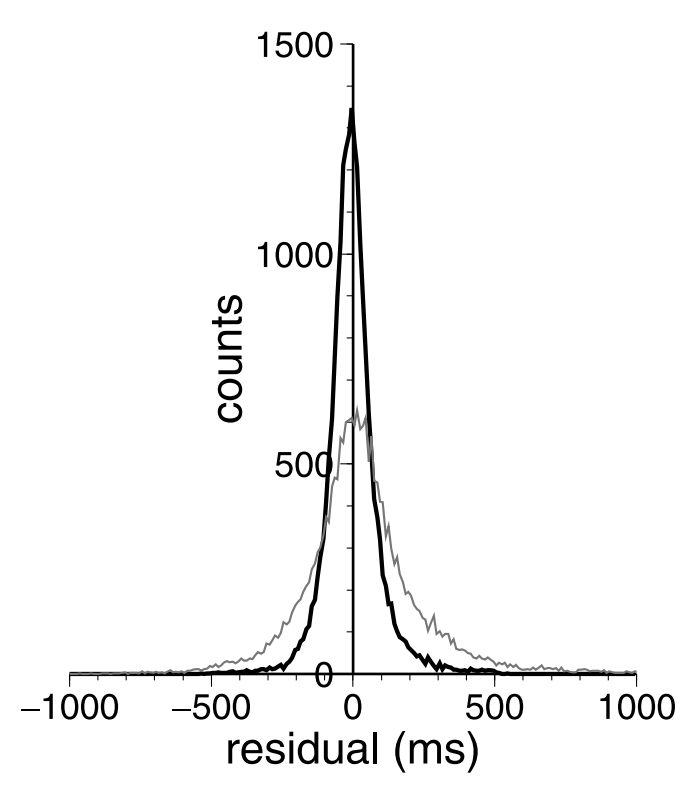

(b) S phase

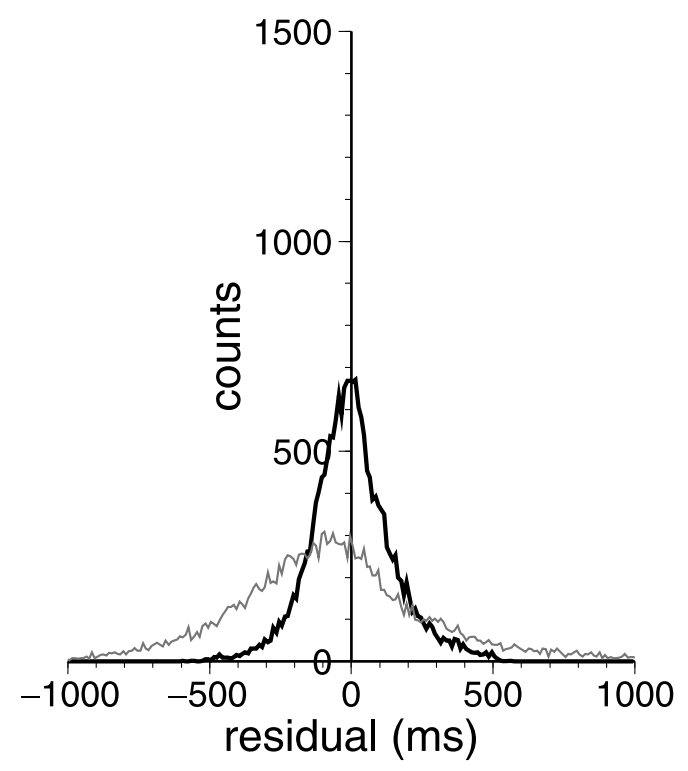

Fig. 6. Distribution of absolute delay time residuals. (a) $P$-phase residuals. Black line: final residuals distribution. Gray line: initial residuals distribution. The final residuals have a mean value $\mu=2 \mathrm{~ms}$ and standard deviation of $\sigma=90 \mathrm{~ms}$, while the initial values were $\mu=32 \mathrm{~ms}$ and $\sigma=208 \mathrm{~ms}$. (b) $S$-phase residuals. Black line: final residuals distribution. Gray line: initial residuals distribution. The final mean and standard deviation values where $\mu=7 \mathrm{~ms}$ and $\sigma=147 \mathrm{~ms}$, while the initial values were $\mu=-42 \mathrm{~ms}$ and $\sigma=400 \mathrm{~ms}$.

horizontal range of $-30 \leq x \leq 30 \mathrm{~km}$ and up to a depth of $20 \mathrm{~km}$ (Figs. 7 and 8). This area correlates with the area of our dense seismic array stations.

\section{Results and Discussion}

4.1 Correlation of the 3D velocity model and geology

While previous studies in central Japan that covered the ISTL region were able to achieve a maximum horizontal 

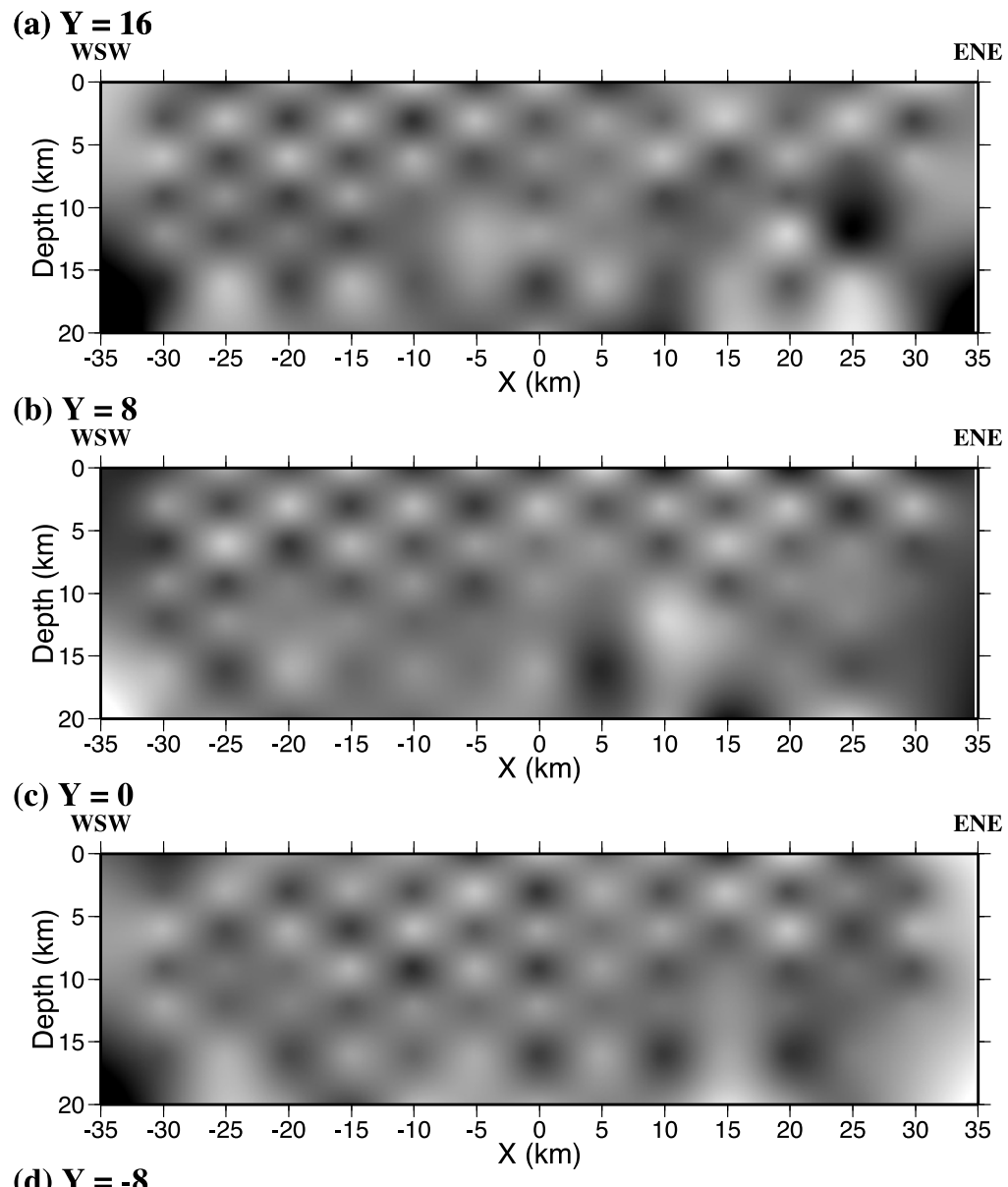

(d) $Y=-8$

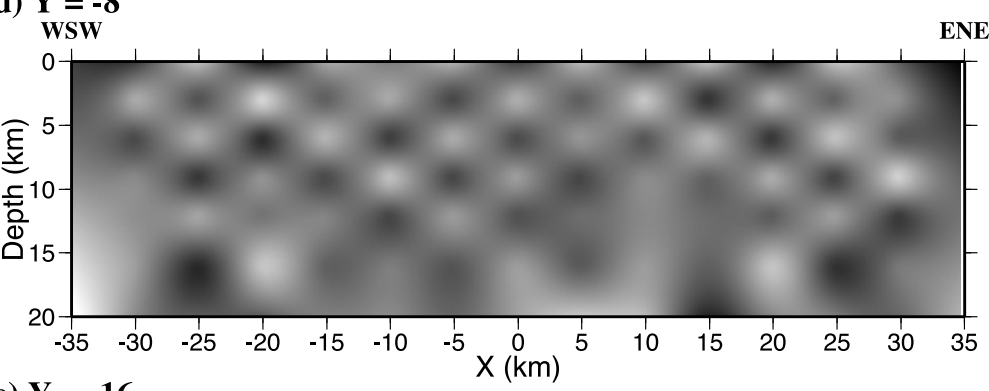

(e) $Y=-16$

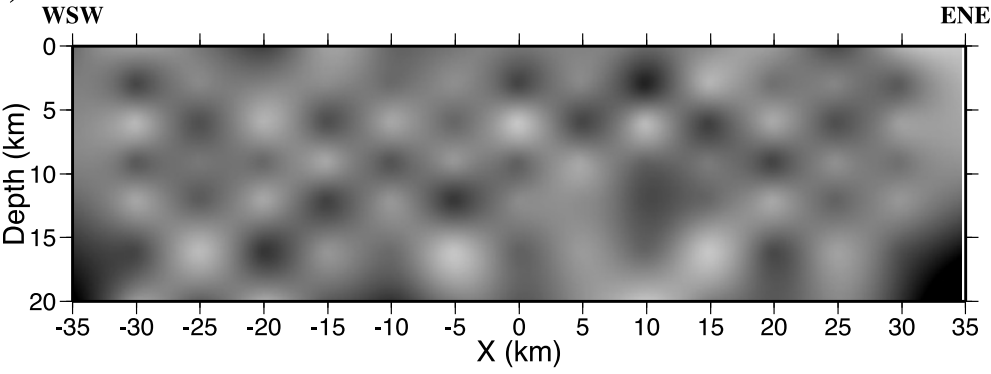

Fig. 7. $P$ wave checkerboard resolution test results. The locations of the cross sections (a) $y=16$, (b) $y=8$, (c) $y=0$, (d) $y=-8$, (e) $y=-16$ are shown in Fig. 4.

resolution of $0.2^{\circ} \sim 0.1^{\circ}$, which is equivalent to $30 \sim 15 \mathrm{~km}$ (Nakajima and Hasegawa, 2007; Kamiya and Kobayashi, 2007), the present study had adequate resolution with a maximum grid spacing of $5 \mathrm{~km}$ for both the $P$ (Fig. 7) and the $S$ waves (Fig. 8). In addition, the maximum vertical resolution of the previous studies is limited by the spacing of the grid points placed every $10 \sim 15 \mathrm{~km}$. This study has achieved sufficient resolution for the surface layers and also for the depth resolution determined by the spacing of grid points placed every $3 \mathrm{~km}$. The inverted $V_{p}$ is presented along five cross sections that intersect the different fault segments of the southern ISTL (Fig. 9). The distinguishing feature in all five cross sections is a wedge-like area with moderately low $V_{p}$ values ranging $5.4-5.8 \mathrm{~km} / \mathrm{s}$, between the surface fault traces of the geological ISTL and the MTL. This wedge seems to become progressively deeper towards 

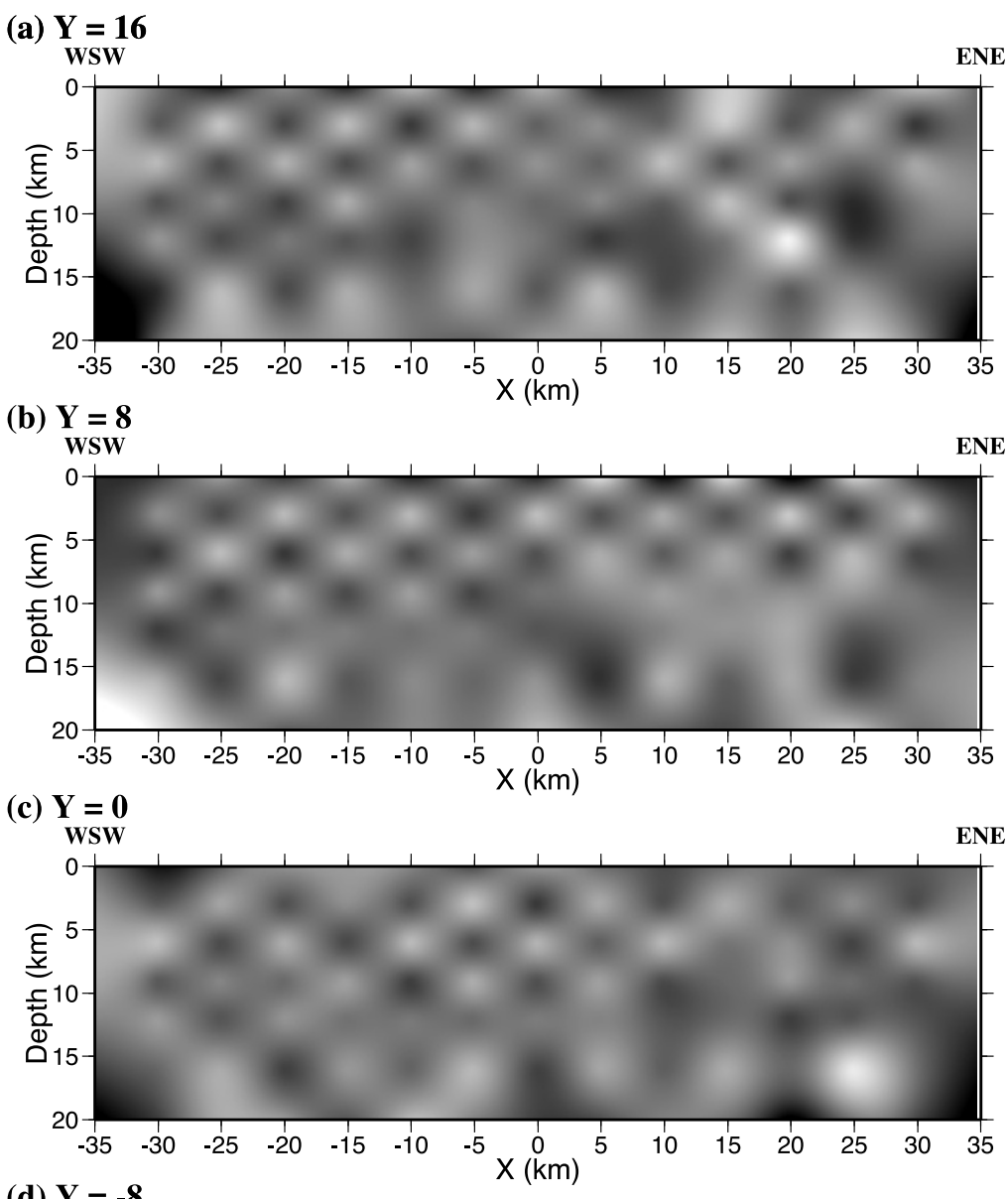

(d) $Y=-8$

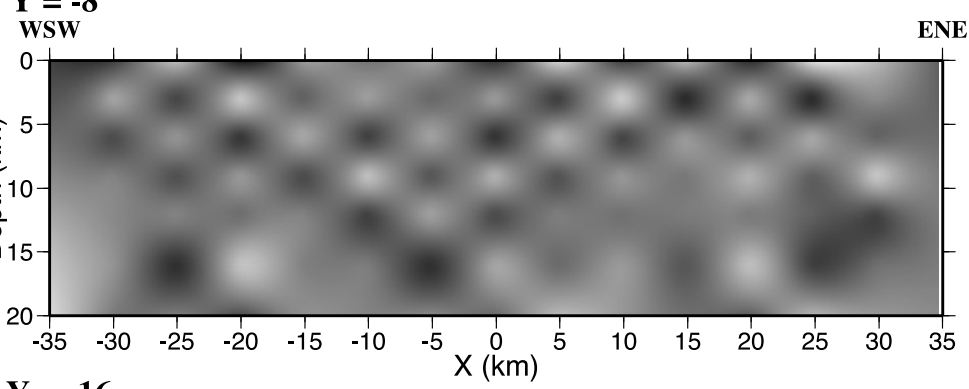

(e) $\mathrm{Y}=-\mathbf{- 1 6}$

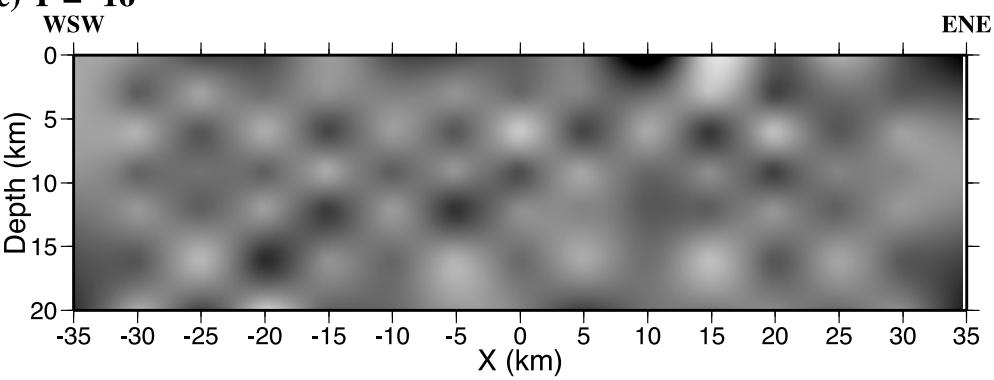

Fig. 8. $S$ wave checkerboard resolution test results. The locations of the cross sections (a) $y=16$, (b) $y=8$, (c) $y=0$, (d) $y=-8$, (e) $y=-16$ are shown in Fig. 4.

the south. In the southernmost cross-sections $(Y=-8$ and $Y=-16)$, a zone of high $V_{p}(6.2 \sim 6.8 \mathrm{~km} / \mathrm{s})$ is located to the east of the wedge structure. Similar high $V_{p}$ values can be also observed to the east of the wedge at the $Y=0$ and $Y=8$ cross-sections, although they seem to be located at depths from 10 to $20 \mathrm{~km}$. The boundary between these two zones dips towards the west with an approximate dip angle of $35^{\circ} \sim 40^{\circ}$. The shallow parts of the cross sections to the east of the ISTL are dominated by velocities lower than $5 \mathrm{~km} / \mathrm{s}$. Similar features can be observed for the $V_{s}$ model (Fig. 10), although not as clear as for the $V_{p}$ due to the low resolutions of the $S$ wave model.

The correlation of $V_{p}$ with specific rocks cannot be interpreted uniquely. On a regional scale however, specific geologic formations can be recognized by their $V_{p}$ trace. To the west of the geological ISTL the $V_{p}$ ranges from 5.4 

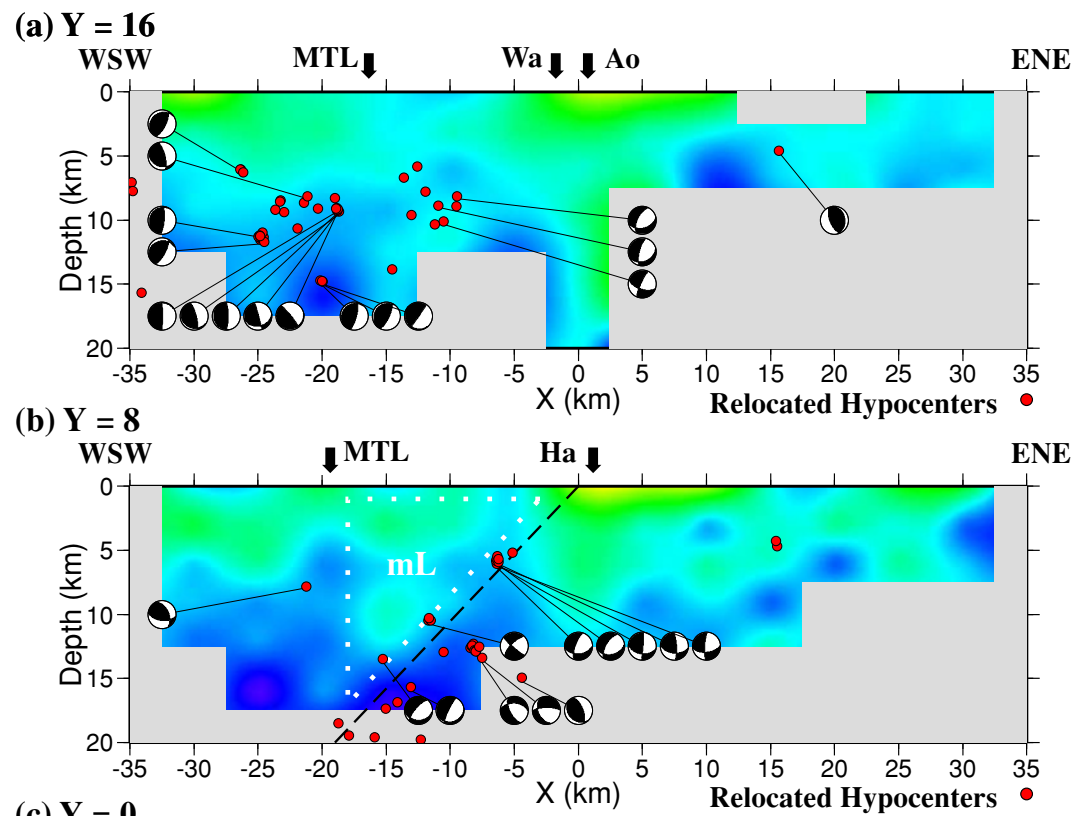

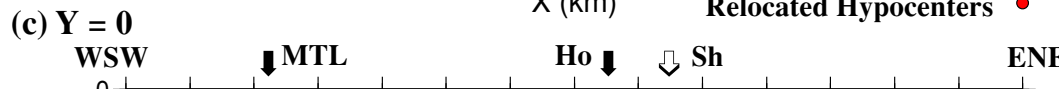

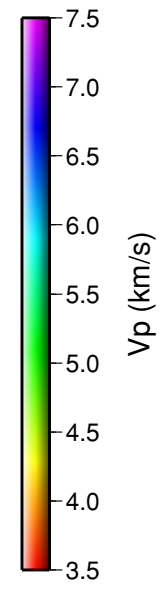

(d) $\mathrm{Y}=-8$
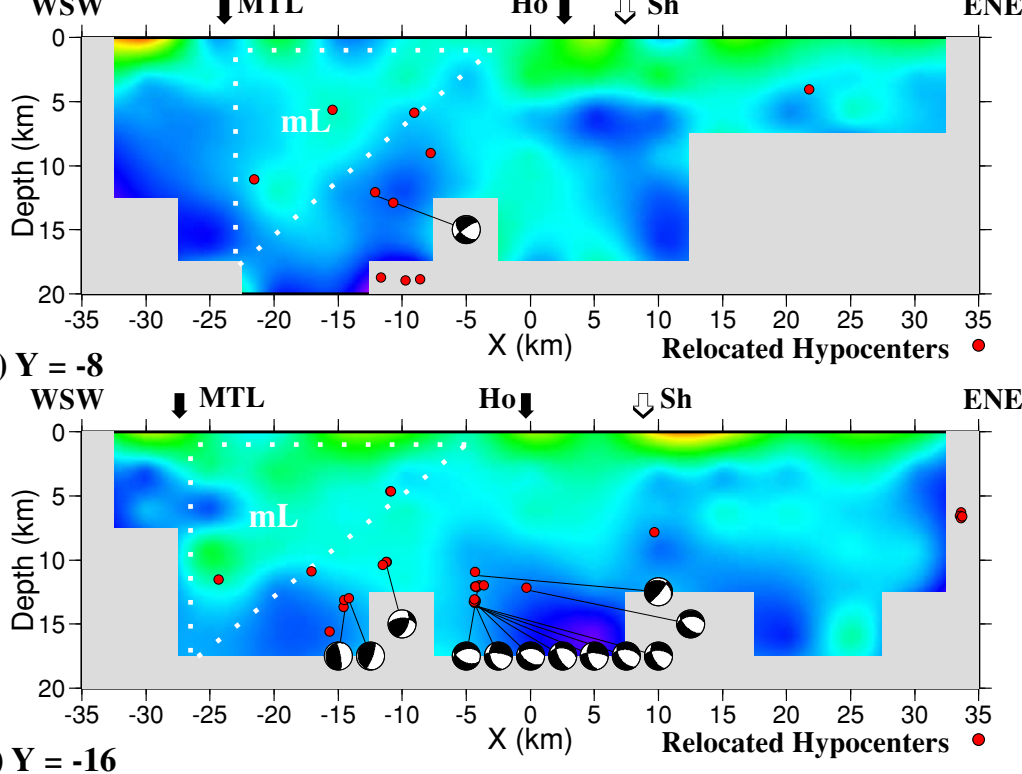

(e) $Y=-16$

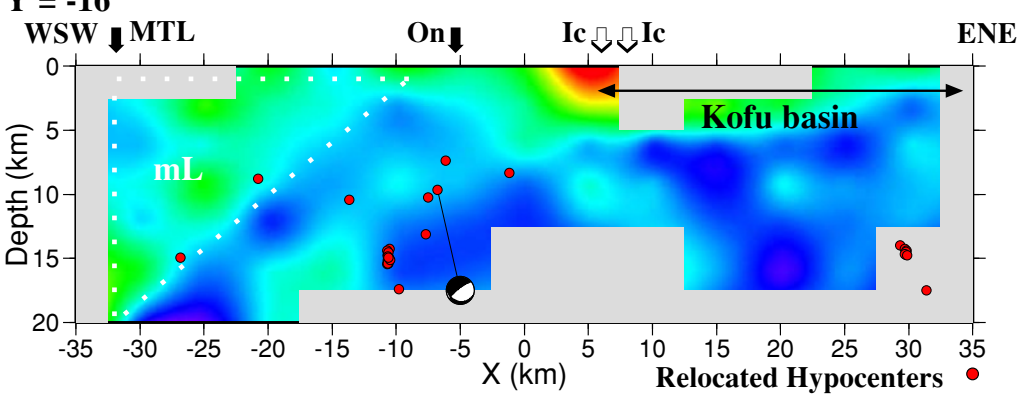

Fig. 9. Vertical slices of the inverted $P$ wave velocity model along the southern ISTL. The cross-sections represent the velocity distribution across each ISTL fault segment including the relocated seismicity $\pm 4 \mathrm{~km}$ from the cross section (red circles), some characteristic focal mechanism solutions after Imanishi et al. (2006) and the surface fault trace location (inverted arrows). The mechanisms are plotted showing the front hemisphere and the viewpoint is set perpendicular to the cross sections. Unresolved areas have been masked out. The locations of the cross sections (a) $y=16$, (b) $y=8$, (c) $y=0$, (d) $y=-8$, (e) $y=-16$ are shown in Fig. 4 .

to $5.8 \mathrm{~km} / \mathrm{s}$. These values are within the range of values expected for the low grade metamorphic and sedimentary rocks comprising the Shimanto belt of the Cretaceous to Tertiary accretionary prism of the southwest Japanese Arc (Taira, 2001). Beneath the Kofu basin and between the geo- logical ISTL and the tectonically active ISTL, the $V_{p}$ ranges from $6.2 \sim 6.8 \mathrm{~km} / \mathrm{s}$ at deep depths, which greatly differs from the velocity range of the rocks of the Shimanto belt. From observations of the outcropping middle crust of the Izu-Bonin arc in the Tanzawa Mountains, we know that it 


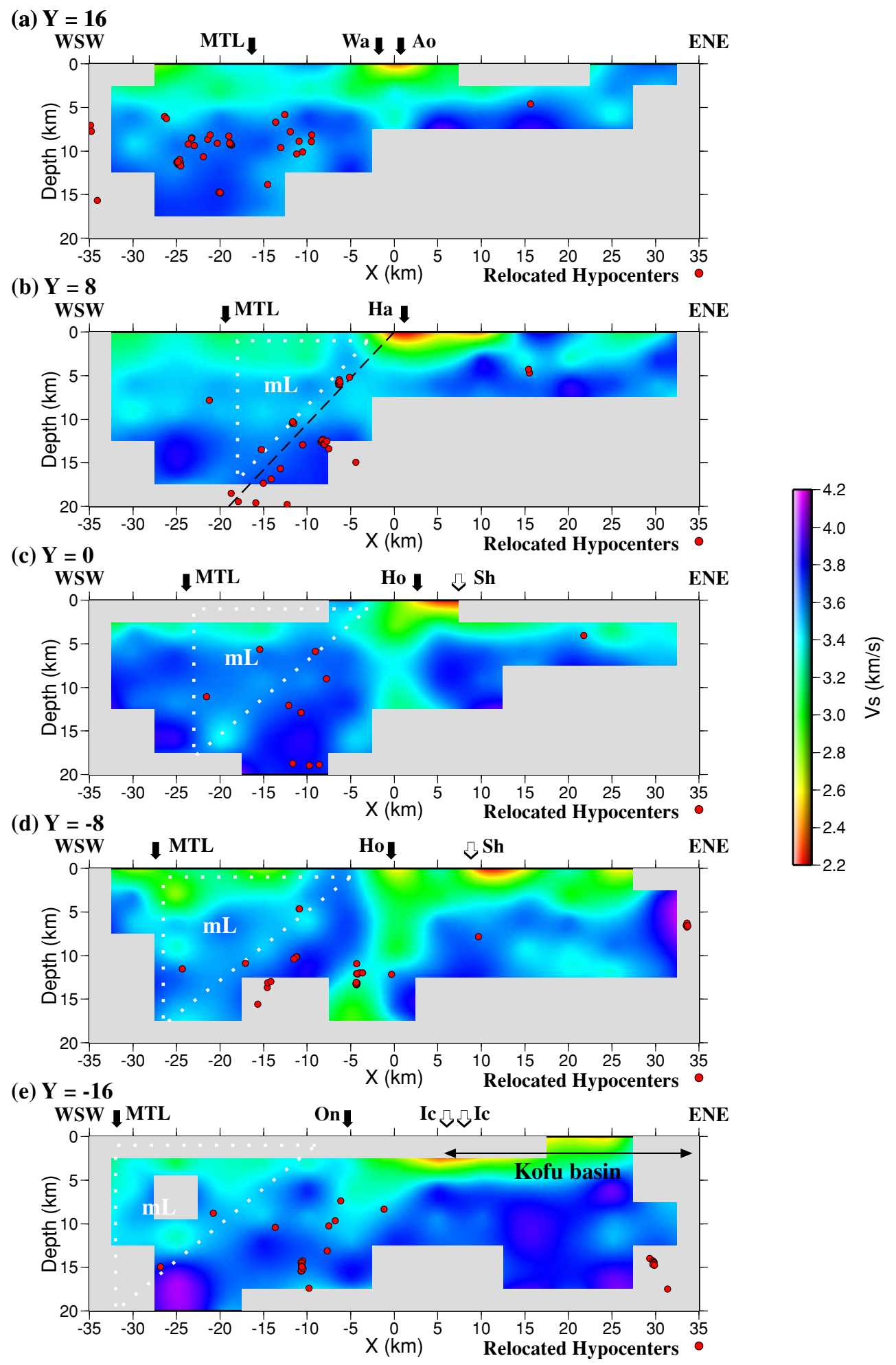

Fig. 10. Vertical slices of the inverted $S$ wave velocity model along the southern ISTL. Red circles represent the relocated seismicity \pm 4 km from the cross section. Unresolved areas have been masked out. The locations of the cross sections (a) $y=16$, (b) $y=8$, (c) $y=0$, (d) $y=-8$, (e) $y=-16$ are shown in Fig. 4.

mainly consists of felsic plutonic rocks (tonalite) (Taira et al., 1998; Kawate and Arima, 1988). The average $V_{p}$ values to the east of the geological ISTL and below the Kofu basin fit the laboratory values for rocks of that composition (Christensen and Mooney, 1995). This evidence suggests that the rocks in the area between the geological and neotectonically active ISTL have the same or similar composi- tion as of the Tanzawa tonalite and probably originate from the Izu-Bonin arc middle crust.

\subsection{Seismicity}

The hypocenters in the southern ISTL are located deeper into the crust than the central ISTL, between 5 and $25 \mathrm{~km}$ depth (Fig. 11). Compared to the locations reported by the JMA, the hypocenters below the Akaishi range are an av- 


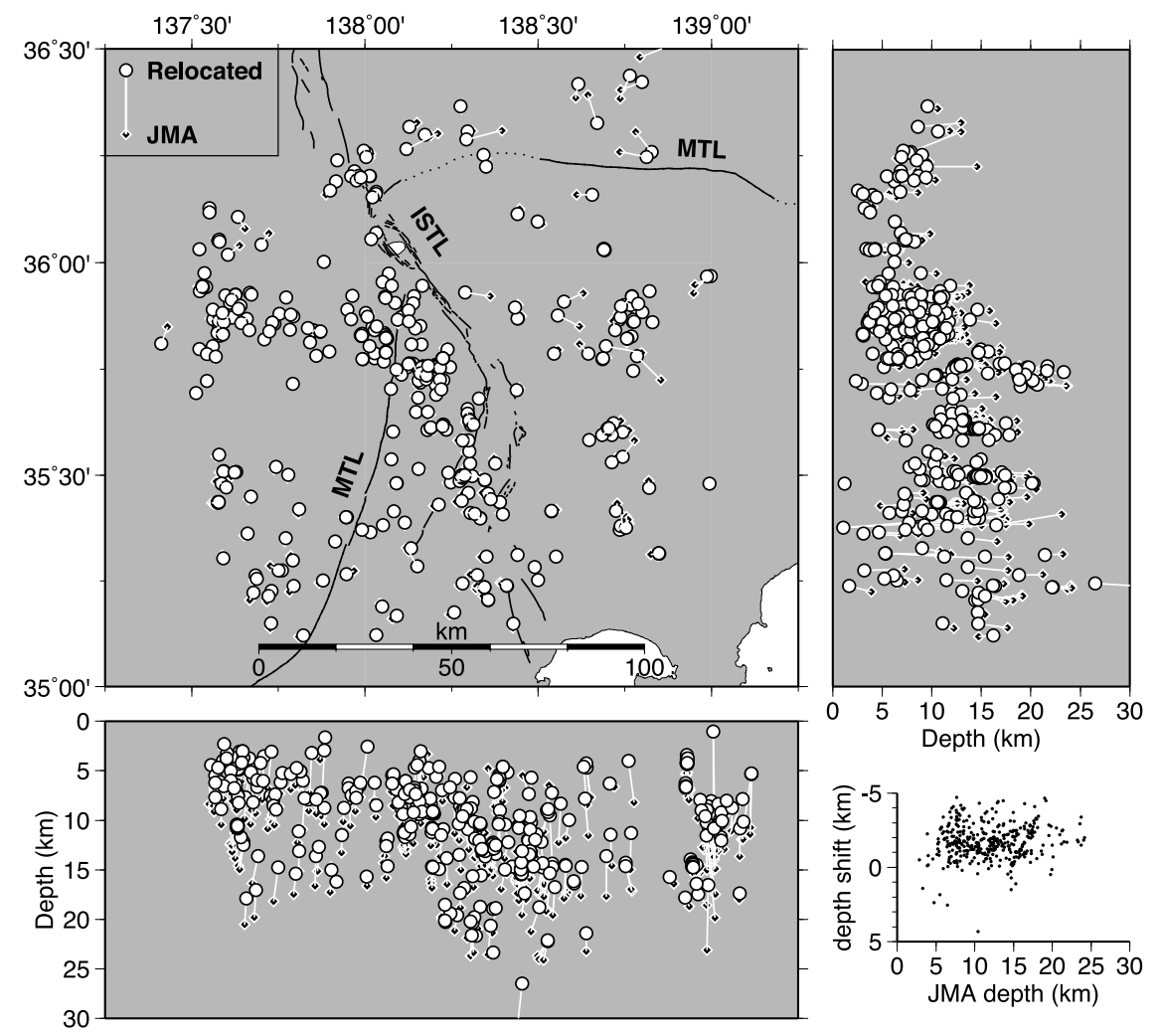

Fig. 11. Hypocenter distribution near the southern segments of the ISTL fault system after the DD tomography relocation. White circles: relocated events. Black diamonds: location determined by the Japanese Meteorological Agency (JMA). White connecting line: shift in the epicentral location and hypocentral depth. The events were relocated an average of $2 \mathrm{~km}$ shallower than the JMA position.

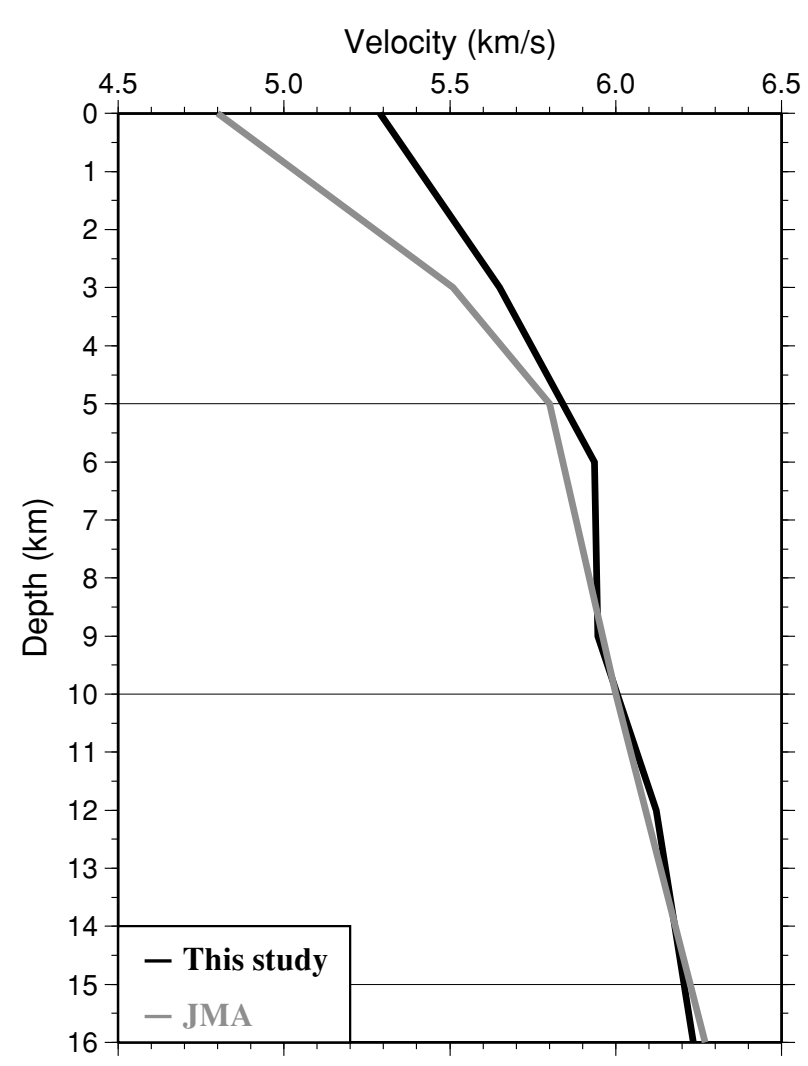

Fig. 12. Comparison of the $V_{p}$ values in the upper-middle crust, between the 1D JMA model (gray line) and the average $V_{p}$ values estimated by this study (black line). The averages are calculated from well-resolved areas within the southern ISTL. erage of $2 \mathrm{~km}$ shallower. The $1 \mathrm{D}$ velocity model used by the JMA for its hypocenter determination represents the average values for all Japan, and is significantly lower than the values estimated by the 3D tomography inversion of the present study. This difference can be clearly seen in the comparison of the $V_{p}$ values in the upper-middle crust, between the 1D JMA model and the average $V_{p}$ values in the southern ISTL area estimated by this study (Fig. 12). Although there is not any obvious clustering of the hypocenters, it is noticeable that in the cross section at $Y=8 \mathrm{~km}$ the hypocenters are almost lined up on the boundary between the high $V_{p}$ zone on the east and the wedge-like area with moderately low $V_{p}$ on the west (Fig. 9(b)), which we considered to be the boundary between the Shimanto-ChichibuSanbagawa belts of the Japanese arc and the accreted IzuBonin arc middle crust. The upwards continuation of the alignment of earthquakes coincides with the surface expression of the Hakushu fault of the geological ISTL, which suggests that the southern ISTL forms a high angle fault that extends deep into the middle crust.

Focal mechanism solutions by Imanishi et al. (2006) are also depicted, suggesting a complex stress regime including both strike slip and reverse faulting. However, in general, as is seen in Fig. 8(a), near the ISTL the reverse fault type is dominant while a strike-slip fault type is dominant near the MTL (Imanishi et al., 2006). The last major event on the Hakushu fault is estimated to have occurred sometime between 6,650 and 7,000 years ago and the fault has recurrence interval of approximately 5,000 years (Toda et al., 2000). This is clear evidence that there is still strain accu- 


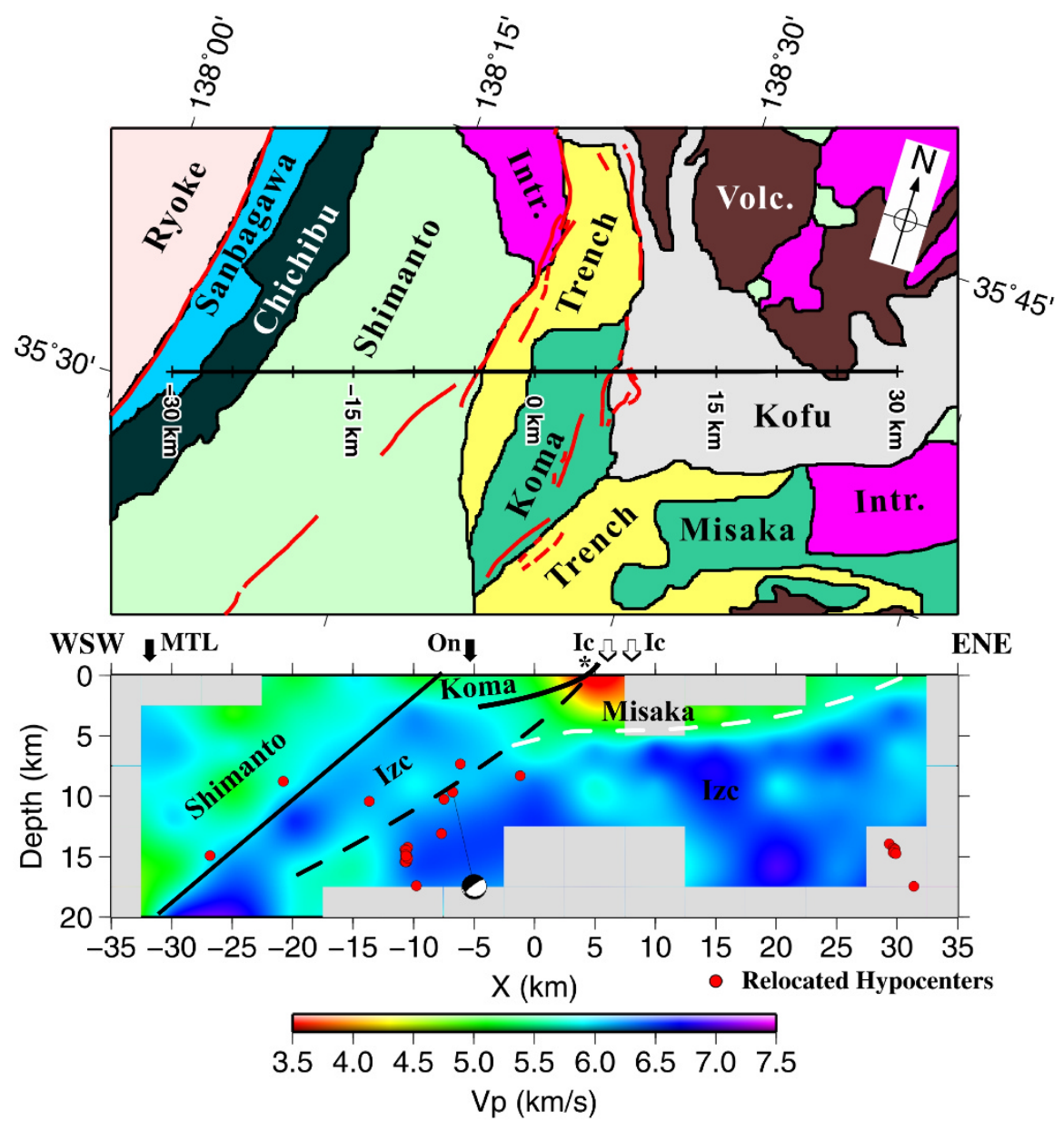

Fig. 13. Major geological units in the southern Japanese Alps area and tectonic interpretation of the tomographic results. Kofu: Kofu basin sediments; Volc.: Volcanic rocks; Trench: Trench fill sediments; Koma: Koma terrane; Misaka: Misaka terrane; Intr.: Granitic intrusions; Shimanto: Shimanto belt; Chichibu: Chichibu belt; Sanbagawa: Sanbagawa belt; Ryoke: Ryoke belt. See also legend in Fig. 2. The $*$ represents the Ichinose fault depth extension after Ikeda et al. (2009). The dashed lines represent the possible boundary between the Koma block and the Misaka block in the Izu-Bonin Arc middle crust (Izc) (black), and the velocity boundary of the Misaka terrane and the Izu-Bonin Arc middle crust (white). The geological ISTL represents the inactive Miocene boundary between the Cretaceous-Tertiary accretionary prism of the southwest Japanese arc and the Koma block of the Izu-Bonin volcanic arc (solid black line starting from the Onajika-toge fault). In contrast, the neotectonically active ISTL is attributed to a reactivation of the boundary fault between the Koma and the Misaka blocks (dashed line starting from the Ichinose fault).

mulation at the deeper parts of the southern ISTL fault system although the main tectonic process that created these faults ended in the Miocene period.

\subsection{Tectonic evolution of the southern ISTL}

Based on a high-resolution reflection/refraction survey, Ikeda et al. (2009) proposed that the southern ISTL forms an active nappe structure with a high slip rate. The neotectonically active strand of the ISTL (Shimotsuburai-Ichinose faults) forms a west-dipping low-angle $\left(\sim 15^{\circ}\right)$ fault that separates the Kofu basin fill on the east from the highly deformed Miocene rocks of the Koma block to the west. They have suggested that the active strand of the ISTL with the low-dip angle is likely to merge downdip to the highangle geological ISTL further to the west. However, the deep geometries of these two faults were not well constrained (figure 6 in Ikeda et al. (2009)), because the reflection/refraction survey area was spatially limited.

The present study investigated the regional crustal structures from the surface to the depth of $20 \mathrm{~km}$ with spatial resolutions of several kilometers. Although the spatial resolutions of shallow crustal structures are lower than those of
Ikeda et al. (2009), a whole picture of the crustal structures including the active strand of the ISTL was well imaged in the present study. The active strand of the ISTL is interpreted to dip westward with higher dip-angles $\left(35^{\circ} \sim 40^{\circ}\right)$, compared with Ikeda et al. (2009). The cross section at $Y=-16 \mathrm{~km}$ provided us a clue to comprehend the tectonic relation between the geological ISTL and the active fault ISTL (Fig. 13). The clear boundary between the accretionary prism of SW Japan arc and the middle crust of the Izu-Bonin arc below the Koma terrane is followed by a localized low-velocity zone inside the Izu-Bonin arc middle crust approximately $10-15 \mathrm{~km}$ to the east (a dashed line in Fig. 13). Local seismicity in the area seems to be related to the localized low-velocity zone inside the IzuBonin arc crust and is characterized by reverse fault mechanism (Imanishi et al., 2006). The surface expression of these boundaries coincides with the Onajika-toge fault trace to the west and the Ichinose fault group to the east (Ikeda et al., 2009), which are parts of the geological ISTL and the neotectonically active ISTL respectively. Similar features of the crustal structure observed in $Y=-16 \mathrm{~km}$ 
could be traced to the cross section of $Y=-8 \mathrm{~km}$. However, the crustal structures change to the northward. Indeed, this lateral change of the crustal structures along the ISTL correlates with lateral variations of the surface geological structure. From the top picture of Fig. 13, the crosssections of $Y=-8$ and $Y=-16$ are located within the Miocene trench fill sediments and Izu-Bonin arc origin volcanic rocks of the Koma block.

We interpret that both geological and active fault ISTL are byproducts of the same major tectonic event that is the arc-arc collision in the Miocene, but express different stages in the collision. The geological ISTL could be a result of the middle Miocene accretion of the Koma terrane. In contrast, the neotectonically active ISTL could be associated with the underthrusting of the accreted parts by the middle crust of the Izu-Bonin arc in the middle Miocene to Pleistocene. Trench excavations across the Ichinose fault suggest that there is an increase of the rupturing in the recent several ten thousand years (Miura et al., 2002). In addition, the activity on the active strand of the ISTL dates back only to 2-3 Ma (Ikeda et al., 2009). These results imply that the active strand of the ISTL could be a reactivated fault within the accreted Middle-Late Miocene Izu-Bonin volcanic arc complexes, possibly the boundary between the Koma and Misaka blocks.

There have been still some discrepancies in interpretations about the tectonic evolutions associated with the ISTL between the previous study (Ikeda et al., 2009) and the preset study, further geophysical and geological studies in the area are required to provide us with information about the detailed whole structures associated with this fault system.

\section{Conclusions}

In order to reveal the tectonic process that controls the earthquake genesis mechanism in the Akaishi range region, two seismic station array observations were conducted across the southern segments of the ISTL active fault system. We revealed the detailed crustal structures, applying the tomography inversion analysis to arrival time data from 434 events observed by the temporary stations. The 3D velocity model obtained shows a thick moderately low $V_{p}$ zone beneath the Akaishi range and a high velocity zone beneath the Kofu basin. The relocated hypocenters in the area of the $Y=8 \mathrm{~km}$ cross section have lined up along this velocity boundary. This boundary coincides with the deeper extension of the Hakushu fault of the ISTL fault system, which has not produced a major event for more than 6,500 years. The observed seismicity suggests that there is still strain build up at the deeper parts of the fault system.

The 3D velocity model is in accordance with the geological structures. The moderately low $V_{p}$ zone fits with the surface expression of the low grade metamorphic rocks that constitute the Chichibu-Shimanto belts of the southwest accretionary prism of the Japanese arc, and the high $V_{p}$ zone coincides with the igneous rocks that form the Izu-Bonin arc crust. Thus we can illustrate the downward continuation of the surface geological units and comprehend the tectonic evolution of the southern ISTL. The middle Miocene to late Pliocene collision of the Izu-Bonin arc with the outer zone rocks of the Japanese arc has produced an extensive thrust fault system that is identified by its surface expression as the southern segments of the ISTL fault system, and governs the predominantly reverse fault character of the earthquake mechanisms that are observed in the area. In the area of the Hakushu fault segment, we were able to image the ISTL as a velocity boundary in the crust and also correlate the local seismicity to that boundary. It forms a $35^{\circ}-40^{\circ}$ reverse fault that extends deep into the middle crust. In addition, the present study provides us with a clue to investigate the relation of the geological ISTL and its active strand, represented by the Onajika-toge fault and Ichinose fault respectively. The geological ISTL is interpreted to be the inactive Miocene boundary between the Cretaceous-Tertiary accretionary prism of the southwest Japanese arc and the Koma block of the Izu-Bonin volcanic arc. In contrast, the neotectonically active ISTL could be attributed to a reactivation of the boundary fault between the Koma and the Misaka blocks.

Acknowledgments. We are most grateful to GSJ, AIST members for the kind provision of the focal mechanism solutions and to $\mathrm{H}$. Zhang for the use of the TomoDD tomography code. We thank the Japanese Meteorological Agency (JMA) and the National Research Institute for Earth Science and Disaster Prevention and the staff at the Earthquake Information Center of the Earthquake Research Institute of the University of Tokyo for providing the waveform data collected at the online stations. We also thank the GEOSYS and JGI seismic crew for helping with the data acquisition. Most of the figures in this paper were created using the GMT program (Wessel and Smith, 1998). This study is supported by the Japanese Ministry of Education, Culture, Sports, Science and Technology under a special project entitled "A high priority investigation in the ISTL fault zone".

\section{References}

Amano, K., Multiple collision tectonics of the South Fossa Magna in Central Japan, Modern Geol., 15(4), 315-329, 1991.

Christensen, N. I. and W. D. Mooney, Seismic velocity structure and composition of the continental crust: A global view, J. Geophys. Res., 100(B7), 9761-9788, 1995.

Fujimori, T., Active faults in the Suwa basin and its evolution as a pullapart basin on the Itoigawa-Shizuoka tectonic line, central Japan, Geogr. Rev. Jpn., 64A, 665-696, 1991 (in Japanese with English abstract).

Geological Survey of Japan, Geological Map of Japan 1:1,000,000, 3rd Edition, 2nd CD-ROM Version, Digital Geoscience Map G-1, Geological Survey of Japan, 2003.

Hirata, N. and M. Matsu'ura, Maximum-likelihood estimation of hypocenters with origin time eliminated using nonlinear inversion technique, Phys. Earth Planet. Inter., 47, 50-61, 1987.

Humphreys, E. and R. W. Clayton, Adaptation of back projection tomography to seismic travel time problems, J. Geophys. Res., 93, 1073-1085, 1988

Ikeda, Y., T. Iwasaki, K. Kano, T. Ito, H. Sato, M. Tajikara, S. Kikuchi, M. Higashinaka, T. Kozawa, and T. Kawanaka, Active nappe with a high slip rate: seismic and gravity profiling across the southern part of the Itoigawa-Shizuoka Tectonic Line, central Japan, Tectonophysics, $\mathbf{4 7 2}$, 72-85, 2009.

Imanishi, K., I. Cho, Y. Kuwahara, N. Hirata, and Y. Panayotopoulos, Focal mechanism solutions of microearthquakes around the southern part of the Itoigawa-Shizuoka Tectonic Line active fault system, Ann Rep. Active Fault Paleoearthq. Res., 6, 55-70, 2006 (in Japanese with English abstract).

Isozaki, Y., Anatomy and genesis of a subduction related orogen: a new view of geotectonic subdivision and evolution of the Japanese islands, Island Arc, 5, 289-320, 1996.

Kamiya, S. and Y., Kobayashi, Thickness variation of the descending Philipine Sea slab and its relationship to volcanism beneath the KantoTokai district, central Japan, J. Geophys. Res., 112(B6), B06302, 2007.

Kano, K., Re-arrangement of the shallow-level structure of Southwest 
Japan Arc due to the collision of the Izu-bonin Arc, Bull. Earthq. Res. Inst. Univ. Tokyo, 77, 231-248, 2002.

Kano, K., K. Kosaka, A. Murata, and S. Yanai, Intra-arc deformations with vertical rotation axes: the case of the pre-Middle Miocene terranes of Southwest Japan, Tectonophysics, 176, 333-354, 1990.

Kato, H., Fossa Magna-A masked border region separating southwest and northeast Japan, Bull. Geol. Sur. Jpn., 43, 1-30, 1992.

Kawate, S. and M. Arima, Petrogenesis of the Tanzawa plutonic complex, central Japan: Exposed felsic middle crust of the Izu-Bonin-Mariana arc, Island Arc, 7, 342-358, 1998.

Koyama, A., Tectonic evolution of the northern Koma Mountains, southern Fossa Magna, central Japan, J. Geosci., Osaka City Univ., 33, 1-48, 1990.

Koyama, A., Collision of the Kushigatayama Block with the Honshu Arc during the middle Miocene, Modern Geol., 15(4), 331-345, 1991.

Koyama, A., The Shimotsutaki Thrust; the bend of the Itoigawa-Shizuoka tectonic line, J. Geol. Soc. Jpn., 94(4), 257-277, 1998.

Kumamoto, T. and Y. Ikeda, Fault geometry and net slip of low angle thrust faults in the Kofu Basin, central Japan, J. Seismol. Soc. Jpn., 46(2), 245258, 1993 (in Japanese with English abstract).

Miura, D., R. Hataya, S. Abe, K. Miyakoshi, D. Inoue, M. Nikaido, T. Tachibana, and N. Takase, Recent faulting history at the Ichinose fault group, southern part of the Itoigawa-Shizuoka Tectonic Line, central Japan, J. Seismol. Soc. Jpn., 55(2), 33-45, 2002 (in Japanese with English abstract).

Nakajima, J. and A. Hasegawa, Deep crustal structure along the NiigataKobe Tectonic Zone, Japan: Its origin and segmentation, Earth Planets Space, 59, e5-e8, 2007.

Nakamichi, H., H. Watanabe, and T. Ohminato, Three-dimensional velocity structures of Mount Fuji and the South Fossa Magna, central Japan, J. Geophys. Res., 112(B3), B03310, doi:10.1029/2005JB004161, 2007.

Sato, H., T. Iwasaki, S. Kawasaki, Y. Ikeda, N. Matsuta, T. Takeda, N. Hirata, and T. Kawanaka, Formation and shortening deformation of a back-arc rift basin revealed by deep seismic profiling, central Japan, Tectonophysics, 388, 47-58, 2004.

Shinohara, M., N. Hirata, and S. Matsuda, Long-term low-power DAT seismic digital data recorder with GPS clock, Zisin, 50, 119-124, 1997 (in Japanese with English abstract).

Soh, W., K. Nakayama, and T. Kimura, Arc-arc collision in the Izu collision zone, central Japan, deduced from the Ashigara Basin and adjacent Tanzawa Mountains, Island Arc, 7, 330-341, 1998.

Taira, A., Tectonic evolution of the Japanese island arc system, Ann. Rev. Earth Planet. Sci., 29, 109-134, 2001.

Taira, A., S. Saito, K. Aoike, S. Morita, H. Tokuyama, K. Suyehiro, N. Takahashi, M. Shinohara, S. Kiyokawa, J. Naka, and A. Klaus, Nature and growth rate of the Northern Izu-Bonin (Ogasawara) arc crust and their implications for continental crust formation, Island Arc, 7, 395407, 1998.

Takagi, K., K. Aoike, and M. Koyama, What happened on the northern tip of the Izu-Bonin arc during 15-10 Ma?, J. Geog., 102, 252-263, 1993 (in Japanese with English abstract).

The Headquarters for Earthquake Research Promotion, National Seismic Hazard Maps for Japan, 94 pp, 2007 (downloadable from: http://www.jishin.go.jp/main/index.html).

Toda, S., D. Miura, K. Miyakoshi, and D. Inoue, Recent surface faulting events along the southern part of the Itoigawa-Shizuoka Tectonic Line, J. Seismol. Soc. Jpn., 52(2), 445-468, 2000 (in Japanese with English abstract).

Wessel, P. and W. H. F. Smith, New, improved version of the Generic Mapping Tools released, EOS Trans. AGU, 79(47), 579, 1998.

Yabe, H., Itoigawa-Shizuoka Tectonic Line, Gendai-no-Kagaku, 6, 147150, 1918 (in Japanese).

Zhang, H. and C. H. Thurber, Double-difference tomography: The method and its application to the Hayward fault, California, Bull. Seismol. Soc. Am., 93(5), 1875-1889, 2003.

Zhao, D., A. Hasegawa, and S. Horiuchi, Tomographic imaging of P and $\mathrm{S}$ wave velocity structure beneath northeastern Japan, J. Geophys. Res., 97(B13), 19,909-19,928, 1992.

Y. Panayotopoulos (e-mail: yannis@eri.u-tokyo.ac.jp), N. Hirata, H. Sato, T. Iwasaki, A. Kato, K. Imanishi, Y. Kuwahara, and I. Cho 